\title{
Preparation and structural characterisation of SBA-15 supported nickel catalysts via sol-gel nickel oxide coatings for dry reforming of methane
}

\author{
R. A. Ahmed, Y. X. Pang, M. Olea \& S. N. B. Hodgson \\ School of Science and Engineering, Teesside University, UK
}

\begin{abstract}
Supported nickel catalysts have been prepared by coating mesoporous silica with nickel oxide through a sol-gel coating technology, other than the conventional impregnation procedure. Sol-gel nickel oxide coatings were first synthesized using nickel nitrate and lactic acid as precursors and then, deposited on the support of mesoporous silica SBA-15. Various synthetic parameters, such as the nickel/lactic acid molar ratio for the synthesis of the sol-gel coatings and the nickel/SBA-15 ratio for the preparation of the catalysts, were investigated. Scanning electron microscopy and energy-dispersive X-ray analysis, X-ray diffraction, thermal analysis and attenuated total reflection fourier transform infrared spectroscopy were used to characterise the nickel oxide sol-gel coatings and the resulting supported catalysts. The catalytic activity was tested using the Catlab integrated system. Results showed that this sol-gel coating route produces uniform nickel oxide thin films and leads to a good distribution of the nickel oxide on the mesopore surface of SBA-15. Compared with the catalyst prepared by impregnation with nickel nitrate salt solutions, the catalysts prepared through the sol-gel coating route are superb in nickel loading and distribution. The mesostructure of the supported catalysts remain unchanged after calcinations at elevated temperatures. Moreover, their catalytic activity towards the dry reforming of methane reaction is higher at temperatures lower than $700^{\circ} \mathrm{C}$.

Keywords: supported $\mathrm{NiO}$ catalysts, SBA-15 silica, sol-gel nickel oxide coatings.
\end{abstract}




\section{Introduction}

Biogas, a mixture of about $60 \mathrm{vol} \%$ of $\mathrm{CH}_{4}$ and $40 \mathrm{vol} \%$ of $\mathrm{CO}_{2}$, is converted into syngas, a 1:1 mixture of $\mathrm{H}_{2}$ and $\mathrm{CO}$, through the process called dry reforming of methane, DRM (Xu et al. [1] and Adu-Gyamfi et al. [2]). Supported Ni catalysts are known one of the very active catalysts for this the reforming reaction. But the $\mathrm{Ni}$ catalysts are easily deactivated, particularly at temperatures higher than $700^{\circ} \mathrm{C}$, because of the formation of coke during the conversion process, via methane decomposition and $\mathrm{CO}$ disproportion reaction (Adu-Gyamfi et al. [2]). Thus, notable efforts have been concentrated on exploring new supported $\mathrm{Ni}$ catalysts in order to obtain high resistance to carbon formation (Adu-Gyamfi et al. [2] and Chen et al. [3]).

The well-known method to incorporate the Ni into suitable support is via impregnation and the simplicity is the most attractive feature of this route, so that it is widely applied in both laboratory experiments and industrial production. Although impregnation route allows high amount of metal to be loaded into the carrier (Tomiyama et al. [4]), it is difficult to control the particle growth during calcination, leading to poor dispersion of the active phase. This work investigates the incorporation of nickel into mesoporous SBA-15 through a solgel coating process. A new nickel oxide sol-gel colloidal suspension is first prepared and then used to coat on the surface of mesopores of SBA-15. Unlike nickel salt, which tends to recrystallise to large crystals after impregnation and drying, the sol-gel colloidal particles, forms a thin amorphous film on the support after drying, which greatly reduces the probability of particle agglomeration in the following calcination and reduction, and thus, highly dispersed nickel over the support can be achieved. The effect of preparing conditions on the active phase loading and dispersion was assessed by means of Scanning electron microscopy and energy-dispersive X-ray analysis (SEM/EDS), attenuated total reflection fourier transform infrared (ATR-FTIR), thermal analysis (TGA/DSC), and x-ray diffraction (XRD) measurements, and the catalytic activity for dry reforming of methane was also evaluated.

\section{Experimental}

\subsection{Preparation procedures}

SBA-15 mesoporous silica support was prepared using modified sol-gel method as reported in our previous paper (Olea et al. [5]). The sol-gel nickel oxide coatings were prepared as follows. Nickel nitrate is first dissolved in deionised water and then precipitated out by adding ammonia solution under vigorous stirring. The precipitate is washed with plenty of water and then dispersed in water again. A specific amount of lactic acid is added and the system is kept under stirring at $60^{\circ} \mathrm{C}$ for a suitable length of time until the system become clear. Different ratios of nickel to lactic acid and nickel concentrations were used as shown in Table 1. The clear sol is directly used to coat SBA-15 for preparation of the supported catalysts. Some pure nickel oxide sol-gels were also coated on 
glass slide for evaluating the film-forming property and used as reference for characterisation. For comparison, a nickel nitrate solution was also prepared and used for preparing the catalyst by impregnation route.

The nickel catalysts supported on SBA-15 were prepared by coating the nickel oxide sols onto SBA-15. Typically, the sol and SBA-15 are mixed in a flask and the suspension stirred at $55-60^{\circ} \mathrm{C}$ for $2 \mathrm{~h}$ and then let the sample dry at $100^{\circ} \mathrm{C}$ in a vacuum oven for $1 \mathrm{~h}$. The dried catalysts are then calcined at $550^{\circ} \mathrm{C}$ for $2 \mathrm{~h}$ with a heating rate of $5^{\circ} \mathrm{C} / \mathrm{min}$, with portions of them uncalcined or calcined at different temperatures for analyses. The processing condition and the final composition of the resulting supported catalysts are also listed in Table 1.

Table 1: Concentrations and $\mathrm{Ni} / \mathrm{H}+$ ratios of sols prepared.

\begin{tabular}{|l|l|l|l|l|l|}
\hline Sol & {$[\mathrm{Ni}] \mathrm{wt} \%$} & $\mathrm{Ni} / \mathrm{H}^{+}$ & Catalyst & $\begin{array}{l}\mathrm{Ni} / \text { Silica } \\
\text { wt/wt }\end{array}$ & $\begin{array}{l}\text { Ni loading } \\
(\mathrm{wt} \%)\end{array}$ \\
\hline 1 & 5 & 1.5 & 4SOLNiOH-1 & $0.5 / 1.0$ & 4 \\
\hline 2 & 5 & 1 & 3SOLNiOH-2 & $0.5 / 1.0$ & 3 \\
\hline 3 & 5 & 0.5 & 2SOLNiOH-3 & $0.5 / 1.0$ & 2 \\
\hline 4 & 5 & 0.25 & 2SOLNiOH-4 & $0.5 / 1.0$ & 2 \\
\hline 5 & 10 & 2 & 3SOLNiOH-A & $1.0 / 1.0$ & 3 \\
\hline 6 & 20 & 1.5 & 6SOLNiOH-B & $2.0 / 1.0$ & 6 \\
\hline 7 & 30 & 1.5 & 19SOLNiOH-C & $3.0 / 1.0$ & 19 \\
\hline $\mathrm{NiNO}_{3}$ & 20 & $/$ & 6IMPNiN-B & $2.0 / 1.0$ & 6 \\
\hline
\end{tabular}

*SOL $=$ sol-gel coating and ${ }^{*} \mathrm{IMP}=$ impregnation method.

\subsection{Characterisation}

XRD data were obtained on a Siemens 500 diffractometer $(\mathrm{Cu} \mathrm{K} \alpha, \lambda=0.1543 \mathrm{~nm}$, $20^{\circ}<2 \Theta<80^{\circ}$ ). SEM micrographs were obtained on a Hitachi S-3400N, Scanning Electron Microscope equipped with energy dispersive spectroscopy (EDS). TEM observations were done with a JEM2010F TEM, with a resolution of $0.23 \mathrm{~nm}$, and accelerating voltage 80 to $200 \mathrm{kV}$. ATR-FTIR of the support and catalyst samples was carried out on a Perkin Elmer 1615 ATR-FTIR spectrometer. The spectra were recorded at a resolution of $4 \mathrm{~cm}^{-1}$ and averaging over 32 scans at ambient temperature. TGA/DSC measurements were carried out for all samples on a STA-1500 simultaneous thermal analysis apparatus. Finally, the $\mathrm{CO}_{2}$ reforming of methane was conducted under atmospheric pressure in the Catlab system (Hiden Analytical Ltd.). Before the reaction, the desired mount of catalysts was reduced in flowing hydrogen $\left(5 \mathrm{Vol} \% \mathrm{H}_{2} / \mathrm{Ar}\right)$. Helium was used as dilution gas during the reaction. A gaseous mixture of methane with $\mathrm{CO}_{2}$ with a volume ratio $\left(\mathrm{CH}_{4}: \mathrm{CO}_{2}=60: 40\right.$ vol\%) was fed into the reactor with the flow rate of 60 and $40 \mathrm{ml} / \mathrm{min}$ for methane and carbon dioxide, respectively. The reaction was conducted at various temperatures from $550^{\circ} \mathrm{C}$ to $700^{\circ} \mathrm{C}$ and lasted for $180 \mathrm{~min}$, with using $0.025 \mathrm{~g}$ of catalyst. 


\section{Results and discussion}

The main goal of this work is to develop highly efficient heterogeneous nickel catalysts for the DRM reaction. For this purpose, mesoporous silica, i.e., SBA15 , with high specific surface area, large pore volume and narrow pore size distribution are chosen as the support, with its characteristics being reported in our previous work (Olea et al. [5]).

\subsection{Characterisation of the sol-gel nickel oxide}

The capability of forming uniform thin coating is the key for this new route of preparing the nickel catalysts supported on SBA-15. Thus, the film-forming property of the sol-gel nickel oxide coatings was first examined. As illustrated in Fig. 1, the prepared sol-gel nickel oxide coating shows very good film-forming capability and form very smooth and flat thin films, implying that a uniform distribution of the coatings on the support's pore surface can be expected. In contrast, the film casting from the nickel nitrate solution shows that the salt recrystallises after drying to form a patterned surface, which means that the salt cannot be evenly spread over the substrate surface, but forms aggregates. Obviously, this is not good for obtaining highly dispersed nickel oxide particles on the support.

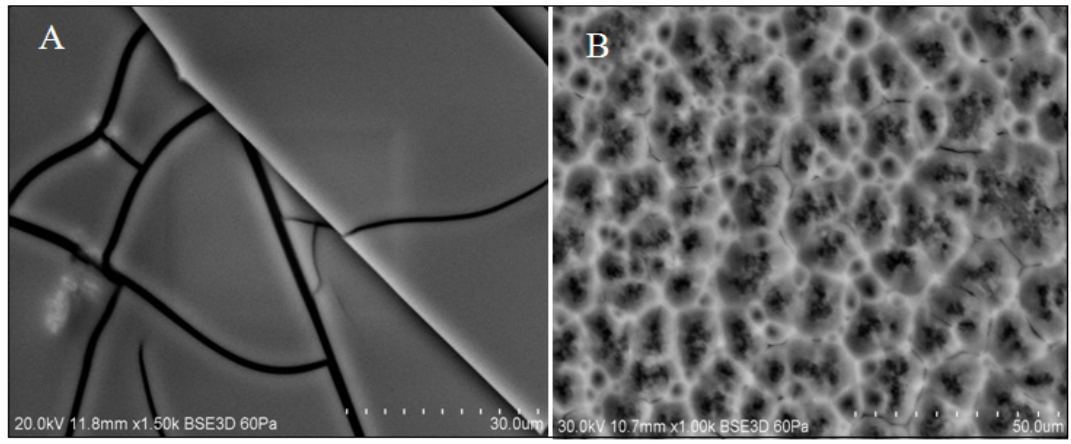

Figure 1: Film-forming property (A) sol-gel nickel oxide coating film; (B) nickel nitrate film.

The calcination of the dried sol-gel (xerogel) thin film was monitored by ATR-FTIR. Figure 2 displays the change of the ATR-FTIR spectra of the xerogel films with heat treatments, with the spectra for each component being also included for reference. The xerogel film shows the typical absorption bands characteristic of the components, lactic acid and nickel hydroxide. For instance, the characteristic bands for lactic acid at $1709 \mathrm{~cm}^{-1}$ (carbonyl vibration), and $1132 \mathrm{~cm}^{-1}$ (hydroxyl) (Brodie-Linder et al. [6]), and the specific bands for nickel hydroxide, at about $609 \mathrm{~cm}^{-1}$ (Ni-O-H bond) and $426 \mathrm{~cm}^{-1}$ (Ni-O bond) (Sharma et al. [7]) are found in the xerogel's spectrum. 
After the heat treatment at $250^{\circ} \mathrm{C}$ for $2 \mathrm{~h}$ at the heating rate of $5^{\circ} \mathrm{C} / \mathrm{min}$, the band for carbonyl group absorption at $1709 \mathrm{~cm}^{-1}$ disappeared, but the hydroxyl group from both nickel hydroxide and lactic acid is retained, meaning that the free lactic acid is decomposed at this temperature. When the sample is heated at temperature higher than $300^{\circ} \mathrm{C}$, all of the hydroxyl absorption bands have disappeared. On the other hand, the Ni-O stretching band at $413 \mathrm{~cm}^{-1}$ becomes stronger for the sol-gel $\mathrm{NiO}$ film heated at higher temperature (Mirji et al. [8]). This suggests that the xerogel film is converted to nickel oxide coating at this temperature. This result is in good agreement with TGA/DSC analysis below.

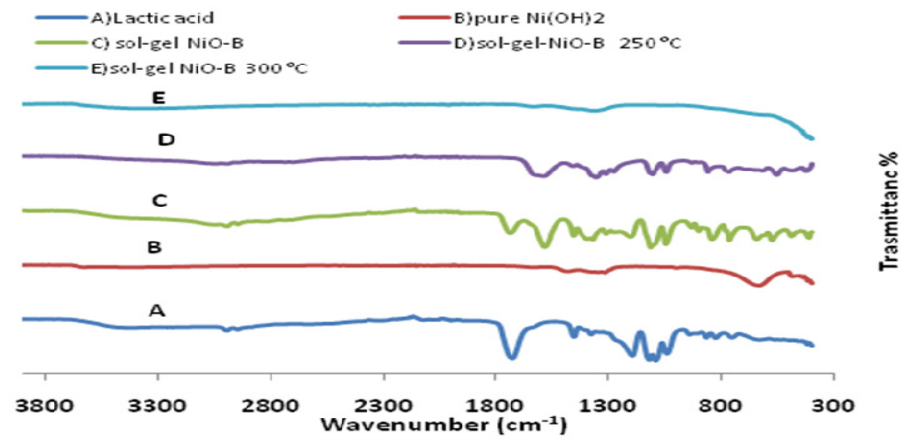

Figure 2: ATR-FTIR spectra for the lactic acid, nickel hydroxide, and nickel oxide sol-gel films heated at various temperatures.

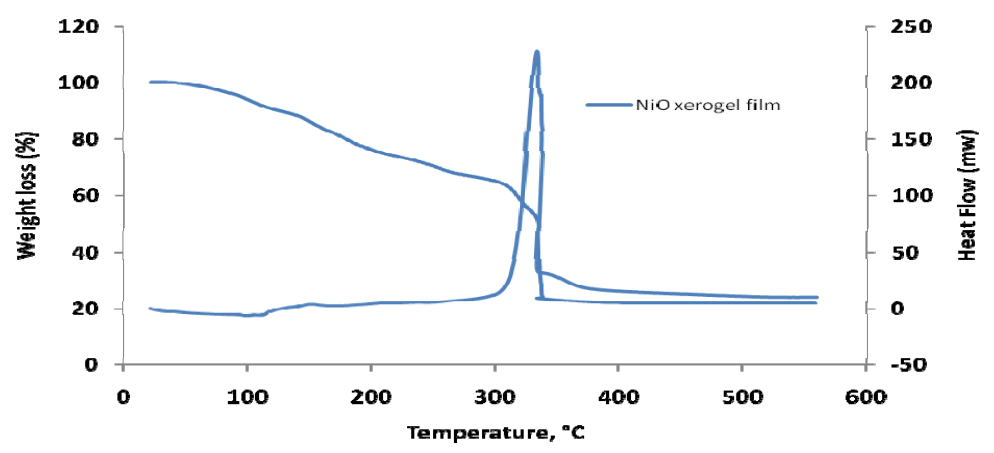

Figure 3: $\quad$ TGA/DSC curves of $\mathrm{NiO}$ xerogel film.

Thermal analysis is also applied to follow the conversion of $\mathrm{NiO}$ xerogel films into nickel oxide. The $\mathrm{NiO}$ xerogel film displays three evident weight loss stages on the TGA curve, as shown in Fig. 3. The initial stage at the temperature lower than $120^{\circ} \mathrm{C}$ comes from the loss of moisture, with a small endothermic peak correspondingly appears on the DSC curve. The gradual weight loss in the temperature range from 120 to $297^{\circ} \mathrm{C}$ loss is due to the evaporation of the free lactic acid and the elimination of water from polycondensation of nickel 
hydroxide. The sharp weight loss at the range from 298 to $339^{\circ} \mathrm{C}$ originates from the burnout of the organic moiety which forms complexes with nickel ions in the xerogel. Accordingly, a very strong exothermic peak appears on DCS curve, reflecting the oxidation process.

\subsection{Characterisation of the supported catalysts}

The SBA-15 supported nickel catalysts prepared by this sol-gel coating technology are characterised using different techniques in order to establish the structure and properties of the catalysts. Figure 4 displays the low-angle XRD results, and it is seen that the scattering patterns are almost the same as that of the support (Olea et al. [5]), showing that the mesoporous structure of the support is maintained after coating with the sol-gel nickel oxide and calcination at $550^{\circ} \mathrm{C}$ for $2 \mathrm{~h}$. All the samples display at least three reflections: (100), (110) and (200), characteristics of the hexagonal array of mesochannels. The interplanar distance, $\mathrm{d}_{100}$, and the size of the unit cell, $a$, are thus calculated based on these patterns and results are listed in Table 2. It is found that these parameters change with the different formulations of the sol-gel nickel oxide coatings. The nickel loading, $\mathrm{d}_{100}$ and $a$ values increase apparently with the increase of the nickel-to-acid ratios of the sol-gel coatings. This is because the higher nickel-to-acid ratio means the higher nickel content in the coating. Catalyst 2SOLNiOH-4 which was prepared using the lowest nickel-to-acid ratio $(0.25$, Table 1$)$, however, behaves differently. Although the low nickel loading level is expected from the low nickel-to-acid, high values in $d_{100}$ and $a$ are also obtained (Table 2). This may result from the excess amount of the acid which undergoes interaction with the hydroxyl group of the support framework, leading to the latter expansion. The nickel-to-SBA-15 ratio has strong influence on the resulting catalysts as well. The nickel loading level increases proportionally with increasing the ratio and $d_{100}$ and $a$ values increase similarly. But the catalyst 19SOLNiOH-C is an exception which was prepared with the highest nickel-toSBA-15 ratio of 3:1. The large surplus amount of sol-gel nickel oxide coating leads to formation of the crystalline nickel oxide aggregates and this may be the reason of the small $d_{100}$ and $a$ values (Table 2). This point will be discussed further from the wide-angle XRD results. Higher unit cell expansion indicates more nickel oxide incorporated inside the silica framework, while smaller unit cell expansion evidences more nickel oxide at the external surface. The typical wide-angle XRD spectra are depicted in Fig. 5. The results show that the nickel loading levels and preparation methods have significant influence on the crystalline structure of the nickel oxide loaded into the support. Patterns (A)-(C) displays the effect of nickel loading on their crystalline states for the supported catalysts prepared via sol-gel route.

There is hardly diffraction peak detected for the catalysts $4 \mathrm{SOLNiOH}-1$ and $3 \mathrm{SOLNiOH}-2$ which has the nickel loading $4 \mathrm{wt} \%$ and $3 \mathrm{wt} \%$, respectively. When the nickel loading increases to $6 \mathrm{wt} \%(6 \mathrm{SOLNiOH}-\mathrm{B})$, some diffraction peaks are detected, but they remain very weak. In contrast, the catalyst 6IMPNiN-B (diffraction pattern D) shows strong diffraction peaks characteristic of nickel oxide, with $2 \Theta=37.3^{\circ}, 43.3^{\circ}, 62.9^{\circ}$ and $79.4^{\circ}$ representing the $\mathrm{NiO}$ 


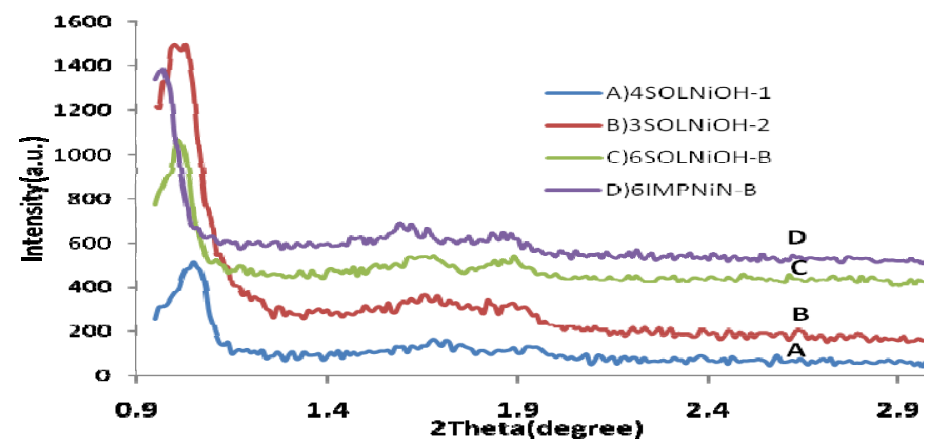

Figure 4: Low-angle XRD patterns of A) 4SOLNiOH-1, B) 3SOLNiOH-2, C) $6 \mathrm{SOLNiOH}-\mathrm{B}$ and D) 6IMPNiN-B catalysts.

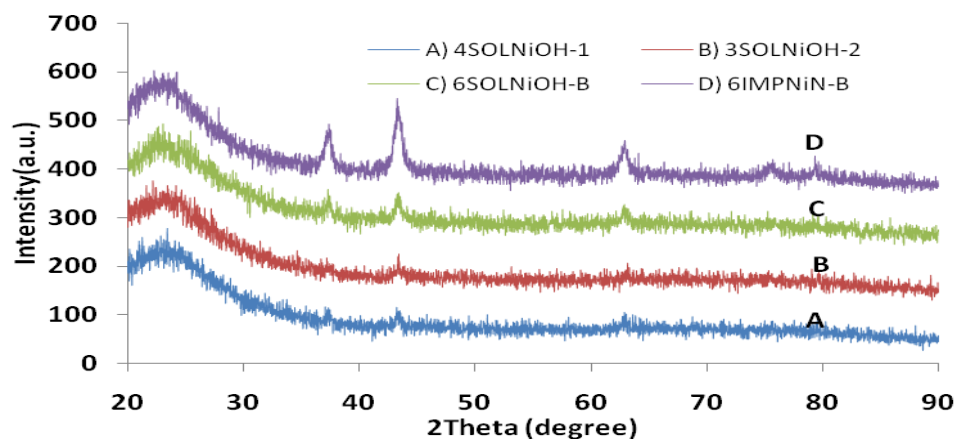

Figure 5: Wide-angle XRD patterns A) 4SOLNiOH-1, B) 3SOLNiOH-2, C) $6 \mathrm{SOLNiOH}-\mathrm{B}$ and D) 6IMPNiN-B catalysts.

Table 2: Unit cell, average crystal size and d-space calculated from XRD results.

\begin{tabular}{|l|l|l|l|}
\hline Catalyst & $d_{100}, \mathrm{~nm}$ & $a, n m$ & $t, n m$ \\
\hline 4SOLNiOH-1 & 8.8 & 10.2 & - \\
\hline 3SOLNiOH-2 & 8.6 & 9.9 & - \\
\hline 2SOLNiOH-3 & 8.5 & 9.8 & - \\
\hline 2SOLNiOH-4 & 9.2 & 10.6 & - \\
\hline 3SOLNiOH-A & 8.8 & 10.2 & - \\
\hline 6SOLNiOH-B & 9.0 & 10.4 & - \\
\hline 19SOLNiOH-C & 8.4 & 9.7 & 13.5 \\
\hline 6IMPNiN-B & 8.2 & 9.5 & 10.1 \\
\hline
\end{tabular}

$a=$ the unit cell parameter is calculated from $a=2 \mathrm{~d}_{100} / \sqrt{3}$, $t=$ average crystal size. 
crystalline planes (111), (200), (220) and (222), respectively. The comparison of diffraction patterns (C) and (D) shows the influence of preparing methods because both supported catalysts have the same nickel loading of $6 \mathrm{wt} \%$. The much weak diffraction peaks on pattern (C) confirms that the sol-gel coating route leads to a better distribution of the nickel oxide spread over the support surface compared with the salt solution impregnation method.

Figure 6 shows the TGA/DSC analysis results for the catalyst $6 \mathrm{SOLNiOH}-\mathrm{B}$ after calculation at various temperatures. The weight loss at initial stage refers to the evaporation of moisture, which is found to vary with the calcination temperature. The uncalcined sample contains the lowest moisture content because the xerogel coating on the support is less hydrophilic due to the existence of the hydrophobic organic moiety. After heating at $250^{\circ} \mathrm{C}$ for $2 \mathrm{~h}$, the sample shows higher moisture intake because the organic phase in the xerogel starts to decompose as indicated in Fig. 3, leading to the formation of the intermediate compounds such as hydroxyls with high moisture affinity. However, when the catalyst is heated at $300^{\circ} \mathrm{C}$, with the moisture content rises to so high as $25.3 \mathrm{wt} \%$. This perhaps is due to the burnout of the organic phase, while the nickel oxide still remains in hydrate form, resulting in the catalyst becomes much hydrophilic. The much less moisture content for the catalysts heated at $550^{\circ} \mathrm{C}$ supports this explanation as the heat treatment at higher temperature converts the hydrate into oxide, reducing the hydrophilicity of the catalyst.

For the DSC curves, the catalysts uncalcined and calcined at $250^{\circ} \mathrm{C}$ demonstrate strong exothermic peaks in the temperature range of 250 to $380^{\circ} \mathrm{C}$, and these peaks are originated from the burnout of the organic phase in the solgel nickel oxide coatings. In contrast, the exothermic peak does not appear for the catalyst heated at temperature of $300^{\circ} \mathrm{C}$, indicating that the organic phase is burnt out when calcining at this temperature. Similar thermal behaviour is observed for the catalyst heated at $550^{\circ} \mathrm{C}$; however, there is a slight difference on TGA curves at high temperature side. The $550^{\circ} \mathrm{C}$ heated catalyst display almost a horizontal line to the end with about $1 \mathrm{wt} \%$ weight loss. On the other hand, the

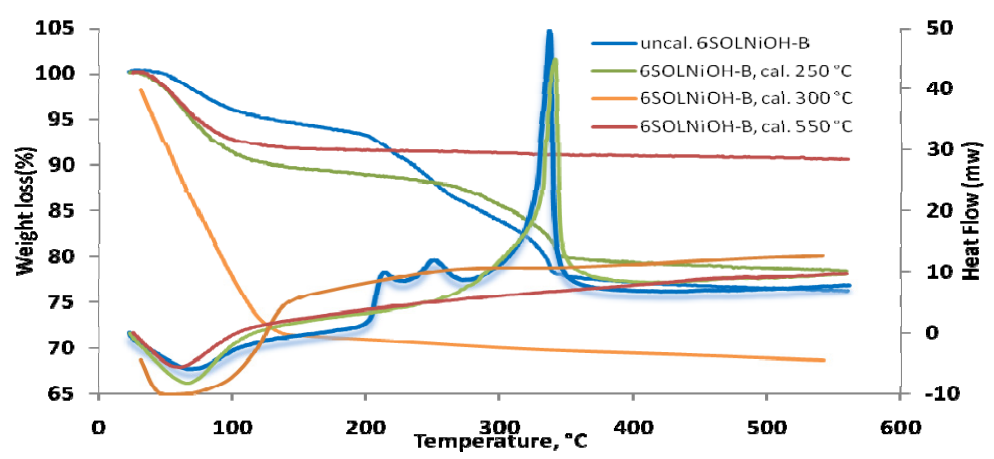

Figure 6: TGA/DSC analysis of 6SOLNiOH-B catalyst, uncalcined, and calcined at various temperatures. 
$300^{\circ} \mathrm{C}$ heated sample shows gradual weight loss over this temperature range. The main reason for this thermal behaviour is that there are still significant amount of hydroxyl groups remained in the catalyst after calcining at $300^{\circ} \mathrm{C}$, which undergo condensation during the heating process of the thermal analysis, leading to the gradual weight loss as increasing temperature. Such thermal behaviour also explains why the $300^{\circ} \mathrm{C}$ calcined catalyst is more hydrophilic than others.

ATR-FTIR spectra of the Ni-incorporated SBA-15 sample 19SOLNiOH-C after calcination at various temperatures are shown in Fig. 7. This sample is chosen because of its high nickel content. In the region of $400-1300 \mathrm{~cm}^{-1}$, the band at ca. $960 \mathrm{~cm}^{-1}$, can be assigned to (Si-O-Ni) vibration. However, this band is corresponding to $977 \mathrm{~cm}^{-1}$ observed in the SBA-15 sample (spectrum not show here), which is assigned to the $\mathrm{Si}-\mathrm{O}$ stretching vibrations of $\mathrm{Si}-\mathrm{OH}$ groups. Therefore, the presence of this band is generally attributed to the formation of SiO-M linkages in metallosilicates. In general, the shift of this absorption band toward the lower wavenumber is considered an indication of metal incorporating into the framework of silica tetrahedral (Dapeng et al. [9]). The vibration band at ca. $1090 \mathrm{~cm}^{-1}$ is assigned to (Si-O-Si) and its wavenumber decreases after heating at $550^{\circ} \mathrm{C}$. Therefore, it indicates that the $\mathrm{Ni}$ may be partly incorporated into the framework. The band at $1600 \mathrm{~cm}^{-1}$ attributed to the presence of the hydroxyl group $(\mathrm{OH})$ from nickel oxide hydrate in the xerogel (Tsai and Wang [10]), is clearly reduced and shifted to high frequency side with increasing temperature, indicating the conversion of the hydrate to oxide.

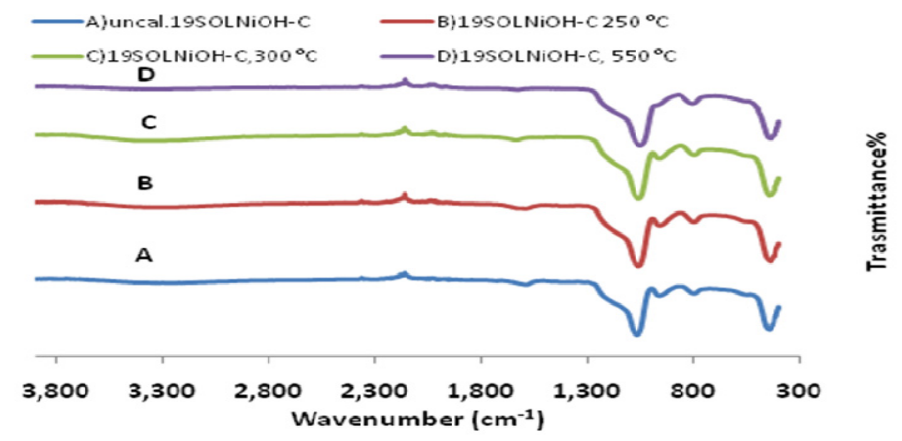

Figure 7: ATR-FTIR results of $19 \mathrm{SOLNiOH}-\mathrm{C}$ catalyst uncalcined and heat treated at temperature 250,300 and $550^{\circ} \mathrm{C}$.

Figure 8 depicts the TEM micrographs for 6SOLNiOH-B and 6IMPNiN-B samples. It is seen that the $6 \mathrm{SOLNiOH}-\mathrm{B}$ has a very neat appearance consisting of long parallel channels in hexagonal array and without any particles visible on the image, indicating the nickel oxide coating uniformly spread over the support (Fig. 8A). On the other hand, the micrograph of 6IMPNiN-B displays a number of dark spots on the image, (Fig. 8B) with the size in the range of 5 to $15 \mathrm{~nm}$ over the mesoporous structure of SBA-15 support, suggesting a large amount of 
nickel oxide presents as aggregates. This result is consistent with that of XRD analysis (Fig. 5), where the 6IMPNiN-B exhibits higher crystallility of nickel oxide, and further confirms that the sol-gel coating route is superior in producing well-dispersed nickel oxide on the surface of the support in comparison with the traditional impregnation process.
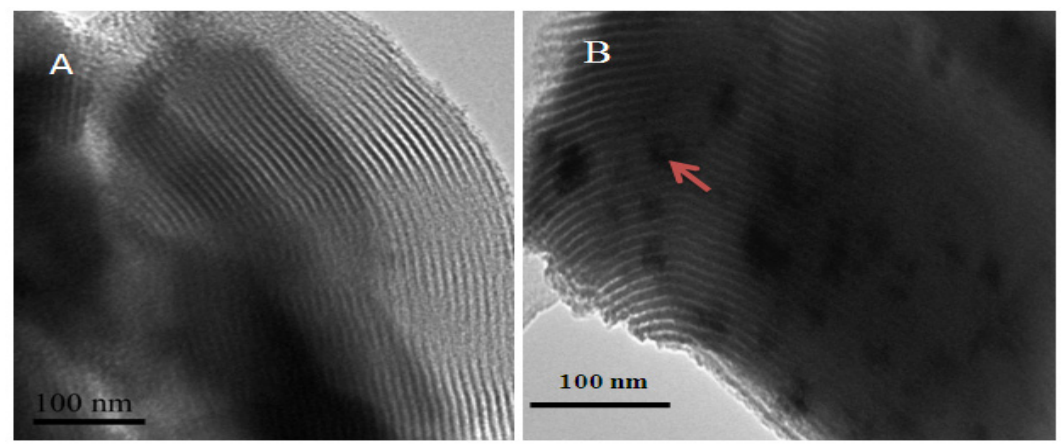

Figure 8: TEM micrograph of A) 6SOLNiOH-B and B) 6IMPNiN-B samples calcined at $550^{\circ} \mathrm{C}$ for 2 hours.

\subsection{Catalytic activity of supported catalyst}

The above results have revealed that the supported catalysts prepared via sol-gel coating technology possesses better distribution of nickel oxide over the support, compared with traditional impregnation technology. Therefore, it is expected such supported catalyst to have higher efficiency because there will be more active sites available if no or less nickel oxide aggregates present in the supported catalyst. For this reason, the DRM with these catalysts was performed at different temperatures, using the 6SOLNiOH-B and 6IMPNiN-B catalysts which have the same nickel loading level. In general, the conversion of reactant gases increases with the temperature for both catalysts as depicted in Fig. 9. However, the 6SOLNiOH-B sample shows higher activity than that of the

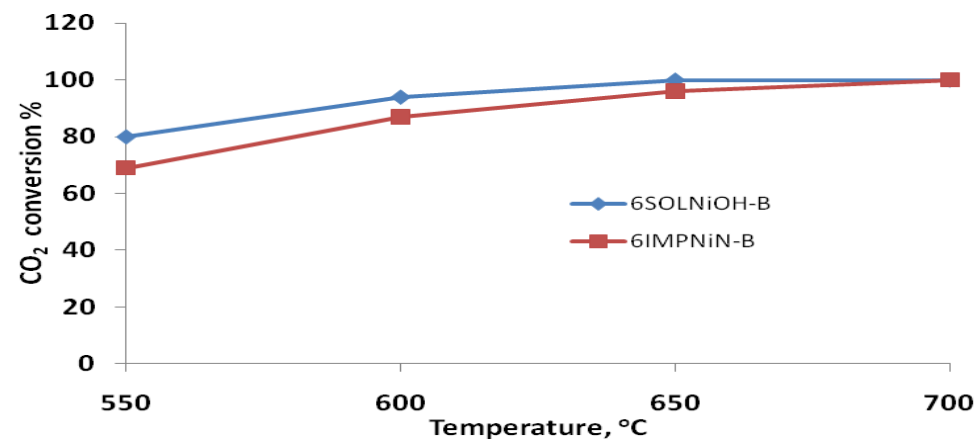

Figure 9: $\quad \mathrm{CO}_{2}$ conversions over $6 \mathrm{SOLNiOH}-\mathrm{B}$ and 6IMPNiN-B catalysts at a temperature range of $550-700^{\circ} \mathrm{C}$. 
6IMPNiN-B one, particularly at a low temperature side. The $\mathrm{CO}_{2}$ conversion using sol-gel coated catalyst is $80 \%$ at $550^{\circ} \mathrm{C}$, about $16 \%$ higher than that of the conventional impregnated catalyst, and $100 \%$ conversion was achieved at $650{ }^{\circ} \mathrm{C}$, whilst this figure is at $700^{\circ} \mathrm{C}$ for the latter. The relatively higher catalytic activity of the catalyst $6 \mathrm{SOLNiOH}-\mathrm{B}$ comes from the improved dispersion of the $\mathrm{Ni}$ active sites, as a result of sol-gel coating process. This result is consistent with XRD result, where less crystallisation and finer nickel particle size is identified (Fig. 5). The stability of $6 \mathrm{SOLNiOH}-\mathrm{B}$ catalyst was also tested for the same reaction at $650^{\circ} \mathrm{C}$. It is shown that after 10 hours running, the catalyst activity remains unchanged.

\section{Conclusion}

Sol-gel nickel oxide coatings consisting of nickel nitrate and lactic acid have been developed and used as the nickel source to prepare nickel catalysts supported onto mesoporous silica SBA-15. The sol-gel coatings form uniform thin films of nickel oxide spread over the support surface, so that ensure the uniform distribution of the catalytic sites. The supported catalysts prepared by sol-gel coating route have not only improved nickel oxide distribution over the support surface, but also show reduced the trend towards crystallisation during calcination, in comparison with those prepared by impregnation with nickel nitrate solution. As a result, the new catalysts demonstrate higher catalytic activity for DRM reaction compared with the catalyst prepared via the conventional impregnation method.

The composition and structure of the supported catalysts can be controlled by means of adjusting the synthetic parameters of the sol-gel nickel oxide coatings and the conditions of coating the SBA-15 support. The loading level of nickel oxide in the resulting catalysts increased with increasing the nickel/lactic acid molar ratio and concentration of nickel precursor in the sols, with the $d_{100}$ and $a$ values increasing correspondingly. The sol-to-support ratio is another determinant for the nickel oxide loading level. Under optimum conditions, no aggregates of nickel oxide are founded in the supported catalyst at $6 \mathrm{wt} \%$ loading level of nickel. Thermal analysis and ATR-FTIR confirm that the nickelcontaining xerogel films remain stable up to $250^{\circ} \mathrm{C}$ and are converted into nickel oxide films at $300^{\circ} \mathrm{C}$ or higher with the burning out of the organic phase.

\section{References}

[1] Xu, J., Zhou, W., Li, Z., Wang, J. and Ma, J. 'Biogas reforming for hydrogen production over nickel and cobalt bimetallic catalysts', International Journal of Hydrogen Energy, 34(16), pp. 6646-6654, 2009.

[2] Adu-Gyamfi, K. A, Villa, R. and Coulon, F. 'Renewable energy, landfill gas and EfW: Now next and future', 10, pp. 4-12, 2010.

[3] Chen, J., Wang, R., Zhang, J., He, F. and Han, S. 'Effects of preparation methods on properties of $\mathrm{Ni} / \mathrm{CeO}_{2}-\mathrm{Al}_{2} \mathrm{O}_{3}$ catalysts for methane reforming with carbon dioxide', Journal of Molecular Catalysis A: Chemical, 235(12), pp. 302-310, 2005. 
[4] Tomiyama, S., Takahashi, R., Sato, S., Sodesawa, T., and Yoshida, S. 'Preparation of $\mathrm{Ni} / \mathrm{SiO}_{2}$ catalyst with high thermal stability for $\mathrm{CO}_{2}$ reforming of $\mathrm{CH}_{4}$ ', Applied Catalysis A: General, 241, pp. 349-361, 2003.

[5] Olea, M., Ahmed, R., Ullah, Q., Kudo, S., Mae, K., Ralebso-Senior, K., Hodgson, S. ' From biomass to valuable chemical and fuels', in Bridgwater A. V. Proceedings of bioten conference on biomass, bioenergy and biofuels 2010. United Kingdom: CPL press, pp. 279-291, 2010.

[6] Brodie-Linder, N., Dosseh, G., Alba-Simonesco, C., Audonnet, F. and Impéror-Clerc, M. 'SBA-15 synthesis: Are there lasting effects of temperature change within the first 10 min of TEOS polymerization?', Materials Chemistry and Physics, 108(1), pp. 73-81, 2008.

[7] Sharma, P. K., Fantini, M. C. A. and Gorenstein, A. 'Synthesis, characterization and electrochromic properties of NiOxHy thin film prepared by a sol-gel method', Solid State Ionics, 113-115, pp. 457-463, 1998.

[8] Mirji, S.A., Halligudi, S.B., Mathew, N., Ravi, V., Jacob, N.E. and Patil, K. R. 'Adsorption of methanol on $\mathrm{Si}(100) / \mathrm{SiO}_{2}$ and mesoporous SBA15', Colloids and Surfaces A: Physicochemical and Engineering Aspects, 287(1-3), pp. 51-58, 2006.

[9] Dapeng, L., Wei-Ni, E. C., Yi, W. Y. L., Armando, B., Raymond, L. and Yanhui, Y. 'A comparative study on catalyst deactivation of nickel and cobalt incorporated MCM-41 catalysts modified by platinum in methane reforming with carbon dioxide', Catalysis Today, 154(3-4), pp. 229-236, 2010 .

[10] Tsai, H.-L. and Wang, C.-S. 'Thermodynamic equilibrium prediction for natural gas dry reforming in thermal plasma reformer', Journal of the Chinese Institute of Engineers, 31, pp. 891-896, 2008. 